\title{
ESPANHA, HABITAÇÃO E COVID-19
}

\author{
SPAIN, HOUSING AND COVID-19
}

ESPAÑA, VIVIENDA Y COVID-19

Tiago Augusto da Cunha ${ }^{1}$

1 Universidade Federal de Viçosa. Departamento de Arquitetura e Urbanismo (DAU), Viçosa/MG. Brasil, e-mail: tiagoac@ufv.br, ORCID: $\underline{\text { https://orcid.org/0000-0002-4634-8497 }}$

ARTICLE INFO

Article history:

Received 2020-04-22

Accepted 2020-06-20

Available online 2020-06-20
Palavras-chave: Habitação. COVID-19. Espanha. Políticas públicas.

Keywords: Housing. COVID-19. Span. Public policies.

Palabras clave: Viviendas. COVID-19. España. Políticas públicas.

RESUMO. Sem dúvida, a gravidade, a intensidade e a amplitude da epidemia de Covid-19 provocarão alterações paradigmáticas na abordagem sobre a problemática habitacional. Apresentamos, assim, o pacote adotado pelo governo espanhol voltado à proteção social da população mais vulnerável durante o ápice da crise sanitária. Neste ensaio, pretendíamos alertar e sensibilizar as autoridades brasileiras sobre a urgência das estratégias que poderiam ser adaptadas e aplicadas à realidade nacional, contribuindo para a prevenção da enfermidade. Além disso, ansiamos contribuir para o enriquecimento do corolário de estratégias visando à provisão e à segurança habitacional, advogando pela perenidade de algumas delas.

ABSTRACT. Undoubtedly, the severity, intensity and dimension of the Covid-19 epidemic will cause paradigmatic changes in housing concerns approach. Thus, in this essay, we present the package adopted by the Spanish government who aimed at social protection of the most vulnerable population stratum during the health crisis apex. We intended to alert and sensitize the Brazilian authorities about strategies that could be adapted and applied to the national reality, contributing to the prevention of the disease. In addition, we look forward to contributing to enrich the corollary of strategies addressing the housing provision, advocating for its continuity.

RESUMEN. Sin dudas, la gravedad, la intensidad y la amplitud de la epidemia de Covid-19 van a provocar alteraciones paradigmáticas en el abordaje sobre la problemática de la oferta de viviendas. Presentamos, así, el abanico adoptado por el gobierno español destinado a la protección social de la población más vulnerable durante el ápice de la crisis sanitaria. En este ensayo, pretendíamos alertar y sensibilizar las autoridades brasileñas sobre la urgencia de las estrategias que podrían ser adaptadas y aplicadas a la realidad nacional, contribuyendo para la prevención de la enfermedad. Además, deseamos contribuir al enriquecimiento del conjunto de actos visando la promoción y seguridad residencial, abogando por la perennidad de algunas de ellas.

\section{Desenvolvimento}

\subsection{Mudanças à vista?}

Não resta dúvida de que a epidemia de COVID-19 deixará marcas permanentes no mundo após seu surgimento em 2019. Certamente ela alterará comportamentos demográficos, sociais, culturais e econômicos; resta saber se o horizonte será utópico ou 
distópico. Há indícios auspiciosos a partir do exemplo espanhol. A sensação é de que a, hoje, inquestionável mercantilização de direitos está abalada pela pandemia. Afirmar isso, não significa ser ingênuo o bastante para imaginar que a abordagem neoliberal será suprimida, embora a crise sanitária tenha sido pedagógica em evidenciar sua selvageria e, logo, suas consequências. Basta lembrar que a crise financeira de 2008 tem suas raízes em subprimes habitacionais.

Mas quais são os indícios de mudança de paradigma? Talvez eles possam ser apreendidos já, a partir do pacote de medidas habitacionais lançado durante a emergência sanitária espanhola. Discuti-lo contribui para novas abordagens da problemática habitacional. Enfoques que priorizam a habitação como direito, não como produto. Perspectivas que partem da importância da habitação como ativo para o enfrentamento de diversos riscos, neste caso, com nome específico: COVID-19. É um também alerta, um chamado à prevenção que inclui o componente habitacional.

\subsection{Quem são os auxiliados?}

Parece importante esclarecer que o leque de medidas emergenciais adotadas não se aplica a toda população espanhola. Todos os atos têm a renda como critério básico de seleção dos beneficiados. O limiar é dado pela vulnerabilidade econômica das famílias.

Em linhas gerais, considera-se vulnerável aquele obrigado a pagar aluguel, financiamento ou hipoteca e que esteja vivenciando situação de desemprego, ĩExpediente Temporal de Regulación de Empleo (ERTE) ${ }^{1}$ ò ou que tenha sido obrigado a reduzir sua jornada e, logo, seus rendimentos para assistir a alguém. Empresários e, especialmente, autônomos também se beneficiam, desde que comprovadamente tenham perdido somas consideráveis de renda. Estes podem apelar para uma moratória de aluguéis e hipotecas se os prejuízos forem de ao menos $40 \%$ nos ganhos da unidade familiar ${ }^{2}$ do mês anterior ao pedido.

Mas não apenas. Além destes, classificam-se como vulneráveis as unidades familiares com renda até 3 IPREM (ñndicador Público de Renta de Efectos Múltiplesò); algo como 1.613,52 ú $\left(\mathrm{R} \$ 8.955,04^{3}\right)$, em 2020. A este valor se adiciona 0,1 IPREM (53,78 ú $\mathrm{R} \$ 297,37$ ) para cada dependente (filhos ${ }^{4}$ ou idosos com mais de 65 anos) por unidade familiar. Ou, 0,15 IPREM $(80,68$ ú - R\$447,77) por filho em unidades monoparentais. Por sua vez, se algum membro da unidade familiar apresentar mais de $33 \%$ de alguma

\footnotetext{
${ }^{1}$ Uma flexibilização momentânea de alguns componentes das leis trabalhistas. Mantém-se o vínculo empregatício, mas sem rendimentos, para se obter uma espécie de seguro desemprego pago pelo governo. Além disso, o governo se compromete a pagar outros encargos trabalhistas, desonerando os empregadores.

2 Compreende-se por unidade familiar :ñ....) la compuesta por la persona que adeuda la renta arrendaticia, su cónyuge no separado legalmente o pareja de hecho inscrita y los hijos, con independencia de su edad, que residan en la vivienda, incluyendo los vinculados por una relación de tutela, guarda o acogimiento familiar y su cónyuge no separado legalmente o pareja de hecho inscrita, que residan en la vivienda.ò

${ }^{3}$ Ptax tomada em 09/04/2020: R\$5,55.

${ }^{4}$ Independentemente da idade.
} 
necessidade especial ou enfermidade que o impeça de realizar qualquer atividade laboral permanentemente, o limite passa a ser 4 IPREM (2.151,36 ú - R\$11.940,05). Importante dizer, os suportes são cumulativos. Se o arrendatário sofrer de paralisia cerebral, enfermidade mental ou defasagem intelectual com grau de deficiência igual ou superior a $33 \%$, ou ainda, se o inquilino possuir algum déficit sensorial igual ou superior a $65 \%$, assim como doença grave que o proíba de realizar qualquer atividade laboral, o limite atinge 5 IPREM (2.689.20 ú - R\$14.925,06).

Em todos esses casos, os critérios de vulnerabilidade combinam aspectos econômicos e físicos. Lembrando que o salário mínimo espanhol, em 2020, é de 950 ú $^{5}$ $(R \$ 5.272,50)$, enquanto no Brasil é de $R \$ 1.045,00$. O salário bruto médio espanhol é de 1.695 ú $^{6}(\mathrm{R} \$ 9.407,25)$. No Brasil, o rendimento médio per capita gira em torno de $R \$$ $1.438,67^{7}$. Em síntese, no caso espanhol, a linha de corte da vulnerabilidade econômica é quase dada pelo salário bruto médio, o que não é pouco.

Além disso, o governo espanhol considera a vulnerabilidade econômica como o resultado do valor gasto com o arrendamento da moradia. Segundo esse critério, se o aluguel ou os valores das parcelas hipotecárias forem iguais ou superiores a $35 \%$ da renda líquida total das rendas combinadas de todos os membros da unidade familiar, essa unidade familiar também será considerada vulnerável. Na verdade, o cômputo dos gastos leva em consideração, inclusive, os consumos de serviços básicos de energia, gás, calefação, água e as despesas com telefonia móvel e fixa.

\subsection{O pacote}

Estes são apenas os parâmetros de seleção. Por mais labirínticos que fossem, eles abarcam um contingente notável da população espanhola, especialmente famílias monoparentais chefiadas por mulheres, domicílios de idosos, com deficientes físicos, desempregados, minorias, imigrantes e marginalizados. Justamente aqueles que mais necessitam amparo.

Uma das maiores demandas dos movimentos sociais espanhóis ligados à questão da moradia $^{8}$, sobretudo após a crise financeira de 2008, dizia respeito ao bloqueio dos despejos. Atualmente, eles foram suspensos por 6 meses. O receio de uma multidão de desalojados, justamente num momento de aumento exponencial dos contágios, foi o empurrão necessário para colocar em prática os anseios dos antes preteridos.

Outra medida foi a prorrogação automática dos contratos de aluguel residencial. $O$ intuito era evitar mudanças de domicílio no momento da crise sanitária. Uma meta indireta era barrar o processo de ñmobilidade residencial descendenteò ou seja, a precarização das

\footnotetext{
${ }^{5}$ Salário mínimo interprofissional. Dados consolidados de 2019.

${ }^{6}$ Fonte: Instituto Nacional de Estadística (INE). Encuesta de Estructura Salarial.

${ }^{7}$ Fonte: Instituto Brasileiro de Geografia e Estatística (IBGE). Pesquisa Nacional por Amostra de Domicílios (PNAD) Contínua.

${ }^{8}$ Plataforma de Afectados por la Hipoteca - PAH (https://pahbarcelona.org/es/portada-cast/), por exemplo.
} 
condições de moradia provocada pela mudança de residência a que estão expostas, especialmente, as famílias mais vulneráveis. Periferização (geográfica e social), insalubridade e adensamento excessivo do domicílio são alguns de seus efeitos. Temia-se que os inquilinos se vissem forçados a aceitar novos valores de aluguel, mais altos, para evitar o despejo. Maiores gastos com moradia significam maiores sacrifícios em relação a outras necessidades básicas: alimentação, educação e saúde.

Houve uma redução de $50 \%$ no valor dos aluguéis e das hipotecas ou uma moratória de 4 meses quando os imóveis pertenciam ao Estado ou a grandes proprietários, com o compromisso de devolução do valor em até 3 anos. Porém, essa ajuda não é cumulativa. Convencionou-se que grandes proprietários são aquelas pessoas físicas ou jurídicas titulares de $1.500 \mathrm{~m}^{2}$ de superfície construída ou mais de 10 imóveis urbanos - excluídos boxes de armazenagem e garagens. Os ñondos buitresò - înedge fundsò (fundos multimercados) -, bancos e imobiliárias se viram prejudicados pela decisão. A tática nos lembra a importância de estoques habitacionais públicos. Eles asseguram maior agilidade na aplicação das disposições emergenciais, além de capitaneá-las. Prestam-se como reservas, freando especulações imobiliárias ao controlar, direta ou indiretamente, os preços da terra, dos imóveis e dos aluguéis. Trata-se de uma estratégia que nos recorda da, em geral desdenhada, questão da posse do imóvel. Diferentemente do que o senso comum crê, a posse - e não a propriedade - pode salvaguardar os mais vulneráveis com mais eficácia e acurácia.

Os não vulneráveis não ficaram necessariamente desprotegidos. Criou-se uma linha de crédito sem custos, nem juros, através do Instituto de Crédito Oficial (ICO) e assegurada pelo Estado, para o pagamento de até seis meses do aluguel. O prazo para pagá-la é de até 6 anos.

Por último, aportou-se um adicional de 100 milhões de euros à dotação original do Plano Estatal de Moradias 2018-2020.

\section{Desafios. Considerações}

De acordo com o próprio governo, o objetivo do conjunto de medidas era bem pragmático. Preservar a renda e assegurar liquidez no pós epidemia, garantindo às famílias capital suficiente para outras necessidades básicas de consumo.

Se essas medidas são o germe de transformações futuras, não há como dizer. Dada a ânsia de reaver os prejuízos financeiros causados pela pandemia, talvez elas sejam rapidamente esquecidas. Feita essa ressalva, não podemos menosprezar os esforços em garantir segurança habitacional, jurídica, econômica e psicológica aos grupos vulneráveis, vítimas de violência de gênero e sem-tetos num contexto de incertezas. 
Por fim, é importante lembrar que o déficit habitacional brasileiro, em 2015, correspondia a 6,355 milhões de residências, segundo a Fundação João Pinheiro. Por outro lado, estimativas apontam que há algo como 6,05 milhões de imóveis desocupados. Assim, outras soluções imediatas para o caso brasileiro têm sido ventiladas por nomes como Raquel Rolnik e Nabil Bonduk. Utilização ou aluguel social de imóveis vazios e refuncionalização temporária do estoque hoteleiro são algumas delas. Todas adaptáveis à realidade brasileira. Bancos de dados sobre imóveis vazios teriam contribuído neste momento, preocupação levantada pelo Estatuto das Cidades desde 2001, pelo menos.

O governo brasileiro tinha, até o momento, uma certa ñantagemò devido aos diferentes momentos de propagação do surto no globo, talvez não seja arriscado dizer que perdemos essa janela de oportunidades para nos prepararmos, supondo que algum dia esse fora o objetivo.

\section{Referências}

Espanha, Real Decreto-ley 8/2020, de 17 de marzo, de medidas urgentes extraordinarias para hacer frente al impacto económico y social del COVID-19. Boletín Oficial del Estado: seção I. Disposiciones generales, Madrid, n 73, p 25853-25898, 18 mar. 2020. Disponível: https://www.boe.es/eli/es/rdl/2020/03/17/8. Acessado em: 10 mar. 2020.

Espanha, Real Decreto-ley 11/2020, de 31 de marzo, por el que se adoptan medidas urgentes complementarias en el ámbito social y económico para hacer frente al COVID-19. Boletín Oficial del Estado: seção I. Disposiciones generales, Madrid, n 91, p 27885-27972, 01 abr. 2020. Disponível: https://www.boe.es/eli/es/rdl/2020/03/31/11. Acessado em: 10 mar. 2020. 